\title{
Aspectos clínicos e terapêuticos de infecção por Mycobacterium bovis em gato doméstico - relato de caso
}

[Clinical and therapeutic aspects of infection by Mycobacterium bovis

\section{A.S. Alves ${ }^{1}$, S.B. Araújol, J.S. Ferreiral, L.K.G. Medeiros ${ }^{1}$, E.L. Oliveira ${ }^{2}$, A.F.M. Dantas ${ }^{3}$, A.P. Souza ${ }^{3}$}

\author{
${ }^{1}$ Programa de pós-graduação - Universidade Federal de Campina Grande - Centro \\ de Saúde e Tecnologia Rural - Patos, PB \\ ${ }^{2}$ Residente - Universidade Federal de Campina Grande - Patos, PB \\ ${ }^{3}$ Unidade Acadêmica de Medicina Veterinária - Universidade \\ Federal de Campina Grande - Patos, PB
}

\begin{abstract}
RESUMO
Este artigo tem como objetivo relatar um caso de infecção por Mycobacterium bovis em um gato doméstico, com seis meses de idade, enfatizando seus aspectos clínicos e terapêuticos. O felino apresentava como histórico a ingestão de leite de vaca não fervido e posteriormente desenvolveu sinais de anorexia, tosse não produtiva e linfadenomegalia. Para elucidação do diagnóstico, foram realizados exames complementares de imagem, hematológicos, citológicos e reação em cadeia da polimerase (PCR). Diante da confirmação de infecção por Mycobacterium, o tratamento foi instituído por meio da associação de três antimicrobianos (enrofloxacino $5 \mathrm{mg} / \mathrm{kg}$, claritromicina $10 \mathrm{mg} / \mathrm{kg}$ e rifampicina $15 \mathrm{mg} / \mathrm{kg}$ ), por via oral, a cada 12 horas, aos quais o animal respondeu positivamente, apresentando significativa diminuição dos sinais clínicos; entretanto, após 60 dias de tratamento, foi a óbito devido a um atropelamento. Conclui-se que a realização do tratamento em gatos com tuberculose pode ocasionar melhora dos sinais clínicos e que, embora de ocorrência rara no Brasil, essa enfermidade deve ser incluída como diagnóstico diferencial das enfermidades infecciosas nessa espécie.
\end{abstract}

Palavras-chave: antimicrobianos, diagnóstico, felino, PCR, tuberculose

\begin{abstract}
This article aims to report a case of Mycobacterium bovis infection in a six-month-old domestic cat, emphasizing its clinical and therapeutic aspects. The feline presented as history the intake of unboiled cow's milk and later developed signs of anorexia, non-productive cough and lymphadenomegaly. Additional imaging, hematological, cytological and polymerase chain reaction (PCR) tests were performed to elucidate the diagnosis. In the presence of Mycobacterium infection, treatment was instituted by the combination of three antimicrobials (Enrofloxacin 5mg/kg, Clarithromycin 10mg/kg, and Rifampicin 15mg/kg) orally every 12 hours, to which the animal responded positively, presenting significant decrease of the clinical signs, however after 60 days of treatment the cat died accidentally, hit by a car on the street. It is concluded that the treatment in cats affected by tuberculosis can cause improvement of clinical signs and that although rare in Brazil, this disease should be included as a differential diagnosis of infectious diseases in this species.
\end{abstract}

Keywords: antimicrobials, diagnosis, feline, PCR, tuberculosis

\section{INTRODUÇÃO}

A tuberculose é uma importante zoonose e tem como um dos seus principais agentes causadores o Mycobacterium bovis, que faz parte do complexo Mycobacterium tuberculosis. Essa bactéria apresenta alta patogenicidade, sendo capaz de infectar, além dos bovinos e humanos, muitas espécies animais, inclusive os gatos (Une e Mori, 2007). No Brasil, a ocorrência de tuberculose em gatos, bem como em outros animais de estimação, é considerada rara (Moretti, 2004). É uma enfermidade

Recebido em 19 de setembro de 2017

Aceito em 4 de abril de 2019

E-mail: aline_sousa88@hotmail.com 
primariamente respiratória, cuja transmissão se dá principalmente pela via aérea ou por meio da ingestão da carne e leite de vacas infectadas (Reilly e Daborn, 1995).

Os sinais clínicos descritos em felinos são variados e inespecíficos, podendo incluir anorexia, linfadenomegalia, úlceras cutâneas, tosse, pneumonia, febre, secreção nasal e dispneia (Gokalp et al., 2011; Gibbens, 2014). O diagnóstico pode ser desafiador, tendo em vista que não há alteração histopatológica patognomônica. Para confirmar o envolvimento micobacteriano, preconiza-se a realização de uma biópsia, e a amostra coletada deve ser submetida à coloração de Ziehl Neelsen (GunnMoore, 2014; Muray et al., 2015). Contudo, a identificação de bacilos não especifica o gênero, podendo ser confundida com outras bactérias, como a Nocardia spp. Assim, a confirmação por meio de um diagnóstico molecular pode ser necessária (Rüfenacht et al., 2011; Gunn-Moore, 2014).

O tratamento de gatos com tuberculose requer uma conscientização dos tutores quanto aos riscos e às complicações potencias. Em animais que apresentem grave comprometimento respiratório ou extensas lesões cutâneas, não é recomendado, devido ao aumento do risco de transmissão (Gunn-Moore e Shaw, 1997). Se o tratamento for considerado, a associação de antimicrobianos como rifampicina, fluorquinolonas e claritromicina tem demonstrado eficácia. Deve-se salientar que a terapia é de longa duração e por tempo indeterminado, a fim de suprimir a doença (Rüfenacht et al., 2011). Objetivou-se, com este trabalho, relatar um caso de infecção por Mycobacterium bovis em um felino, enfatizando seus aspectos clínicos e terapêuticos.

\section{CASUÍSTICA}

Foi atendido, na clínica médica de pequenos animais, do Hospital Veterinário da Universidade Federal de Campina Grande (HV-UFCG), na cidade de Patos, Paraíba, um felino macho, sem raça definida (SRD), de seis meses de idade, com histórico de anorexia e tosse não produtiva há 30 dias. Relatou-se que era oferecido leite de vaca não fervido, além de ração, prática cultural ainda presente em algumas regiões de interior. Tinha acesso à rua, não era vacinado nem vermifugado.
Ao exame físico, o animal apresentava-se ativo, com mucosas coradas, hidratado, com escore corporal 2 (1-5); frequências cardíaca, respiratória e temperatura retal normais; ausculta cardiorrespiratória sem alterações e linfonodos mandibulares, pré-escapulares e poplíteos acentuadamente reativos. Após o exame físico, foi coletada amostra de sangue e solicitado hemograma, bioquímica sérica renal (ureia e creatinina) hepática (ALT, FA e albumina), exame radiográfico do tórax, ultrassonografia abdominal e citologia dos linfonodos mandibulares por meio de punção aspirativa por agulha fina (PAAF). No hemograma, observouse leucocitose por neutrofilia. Não foram observadas alterações na bioquímica sérica.

No exame radiográfico, foi possível evidenciar um padrão pulmonar misto, sendo esse moderadamente intersticial, estruturado com aspecto micronodular e discretamente alveolar, com presença de broncogramas aéreos, distribuídos difusamente pelos campos pulmonares e obliterando, de forma parcial, a silhueta cardíaca (Fig. 1). Na ultrassonografia abdominal, foi possível observar hipertrofia generalizada dos linfonodos abdominais (maior medida 4,32x2cm), estando esses com superfícies irregulares, ecogenicidade mantida, ecotextura heterogênea, com múltiplos pontos hiperecoicos, com discreta formação de sombra acústica posterior, difusos no parênquima. Demais órgãos abdominais apresentavam-se sem alterações ultrassonográficas.

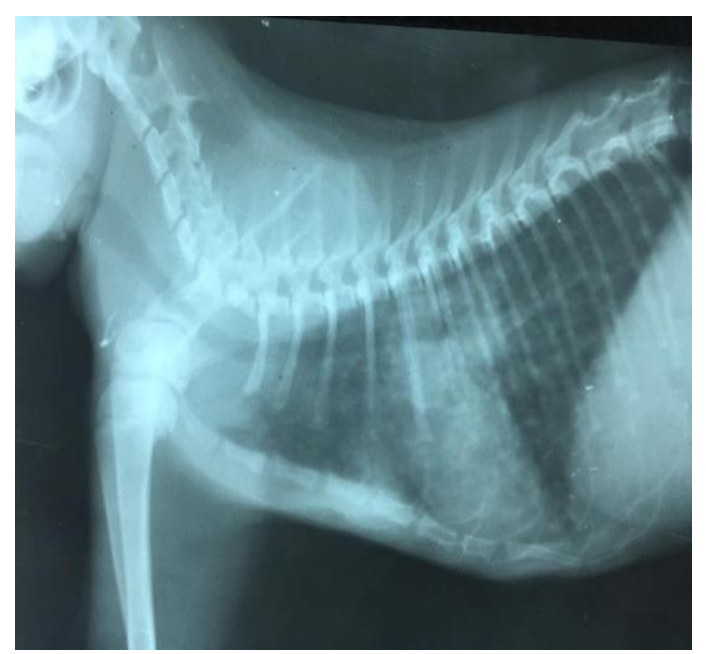

Figura 1. Exame radiográfico de um felino infectado por Mycobacterium bovis. 
No exame citológico dos linfonodos mandibulares, os esfregaços foram primeiramente corados pelo panótico rápido, sendo visualizada na microscopia uma acentuada quantidade de neutrófilos degenerados associados a macrófagos reativos em meio a debris celulares, contendo imagens negativas de bactérias tipo bacilos, o que caracteriza um processo inflamatório piogranulomatoso de origem bacteriana.

Posteriormente novas lâminas foram coradas pela coloração de Gram e Ziehl Neelsen. Observou-se, no Ziehl Neelsen, uma acentuada quantidade de bactérias tipo bacilos álcool-ácido resistentes, compatíveis com Mycobacterium spp. Diante da suspeita, foi realizada a biopsia incisional do linfonodo poplíteo, sendo fixado em formalina $10 \%$ para posterior processamento histológico e imuno-histoquímica (IHQ). Foi utilizado o anticorpo anti-Mycobacterium spp., verificando-se forte imunomarcação no tecido analisado. A amostra também foi encaminhada para a realização de PCR, para identificação do subtipo de Mycobacterium e desfecho do diagnóstico.

Mediante a associação dos sinais clínicos, exames de imagem, citologia e PCR, estabeleceu-se o diagnóstico de tuberculose felina por Mycobacterium bovis. Como tratamento, optou-se pela associação de três antibióticos: enrofloxacino (5mg/kg, BID), sendo essa a fluorquinolona mais acessível ao tutor, claritromicina $(10 \mathrm{mg} / \mathrm{kg}$ BID) e rifampicina $(15 \mathrm{mg} / \mathrm{kg}$ BID), todos por via oral. O retorno do paciente após 30 dias de tratamento revelou efetividade dele, observando-se significativa diminuição dos linfonodos mandibulares e poplíteos (Fig. 2), e, segundo relato do tutor, diminuição da frequência das tosses, melhor apetite e estado geral, estando o animal mais ativo.

Após 60 dias de tratamento, o animal sofreu traumatismo por atropelamento e foi a óbito, o que impediu a continuidade do tratamento e a conclusão de sua eficiência.

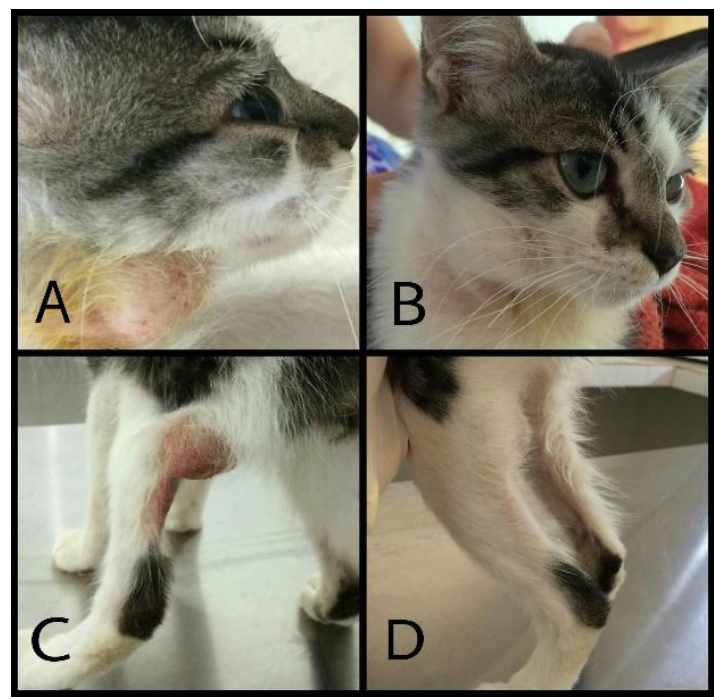

Figura 2. A - Aumento de linfonodo mandibular em felino infectado por Mycobacterium bovis. B - Redução do tamanho de linfonodo mandibular em felino após tratamento. C - Aumento de linfonodo poplíteo. D - Redução do tamanho do linfonodo poplíteo após tratamento.

\section{DISCUSSÃO}

Casos de tuberculose em felinos já foram descritos em diversos países (Monies et al., 2006; Gokalp et al., 2011). No Brasil, a infecção por Micobacterium bovis ainda não foi relatada na espécie felina. Porém, a enfermidade pode estar sendo subdiagnosticada, visto que não existem sinais patognomônicos, podendo ser confundida com doenças causadas por outros agentes infecciosos. Portanto, deve ser considerada como diagnóstico diferencial para diversas doenças infecciosas de felinos.

A principal forma de infecção da tuberculose ocorre pelo consumo de leite e carne contaminados de origem bovina (Reilly e Daborn, 1995). Na espécie felina, os aspectos epidemiológicos da tuberculose são complexos, pois, além do consumo dos alimentos previamente citados, o hábito de caçar é considerado um fator de risco, pois algumas espécies de ratos podem albergar $M$. bovis e $M$. microti (Gunn-Moore, 2014); além disso, já foram relatados dois casos de tuberculose felina por infecção nosocomial (Muray et al., 2015).

O felino apresentado neste relato tinha como dieta oferecida leite de vaca cru, prática comum em região de interior, e, uma vez que foram 
detectadas amostras de leite contaminadas por $M$. bovis de vacas infectadas no estado da Paraíba (Ramos et al., 2016), sugere-se que a contaminação tenha ocorrido por essa via. Os principais sinais clínicos observados no animal deste relato foram anorexia, tosse não produtiva e linfadenomegalia. Esses sinais estão de acordo com os observados por Lisle et al. (1990), que descreveram alterações clínicas em 57 felinos infectados por $M$. bovis. Os sinais clínicos observados eram bastante variados e incluíam linfadenopatia, perda de peso, envolvimento do trato respiratório, depressão e lesões cutâneas, sendo esses dois últimos não observados no caso aqui relatado.

O felino deste relato apresentou boa resposta ao tratamento instituído, fato que também ocorreu em dois casos de felinos diagnosticados com tuberculose associada ao $M$. bovis no Texas, EUA, tratados com rifampicina, marbofloxacina e claritromicina, em que um se apresentava com linfadenopatia, dispneia, taquipneia e tosse produtiva, com radiografia torácica evidenciando consolidação broncointersticial pulmonar grave, com nódulos maldefinidos e doença traqueobrônquica, e o outro era assintomático, mas com alterações nodulares e consolidação peri-hilares consistente, com granulomas vistos em radiografia (Ramdas et al., 2015).

Por se tratar de uma zoonose, a indicação de realização do tratamento é controversa, principalmente em animais com envolvimento sistêmico, tendo em vista que esses fatores aumentam o risco de infecção para outros animais e humanos (Gunn-Moore e Shaw, 1997). Além disso, vale salientar que indivíduos com infecção pelo HIV ou submetidos à quimioterapia são mais susceptíveis à infecção (Rüfenacht et al., 2011). Porém, mesmo após o esclarecimento sobre os riscos de contaminação, o tutor optou pela realização de tratamento clínico, levando em consideração a ausência de pessoas imunossuprimidas na residência, bem como o elevado vínculo afetivo com o animal.

Para evitar uma possível resistência antimicrobiana, instituiu-se o tratamento mediante a associação de três antibióticos: enrofloxacino, claritromicina e rifampicina, adequados de acordo com as condições financeiras do tutor, por tempo indeterminado, com avaliações periódicas. Outras combinações de antibióticos também foram consideradas eficientes. Associações de azitromicina com marbofloxacina ou rifampicina foram realizadas em cinco felinos e todos mostraram uma resposta satisfatória, com diminuição acentuada dos sinais clínicos e alterações radiográficas (Gibbens, 2014). A remissão dos sinais clínicos e radiográficos também foi descrita após o uso da associação de rifampicina, marbofloxacina e claritromicina (Ramdas et al., 2015). Visto que a evolução do quadro clínico do animal era satisfatória, estando este mais ativo, com apetite aumentado e considerável diminuição da linfadenomegalia e dos episódios de tosse após 60 dias de tratamento, acreditava-se que ele teria prognóstico favorável, porém o desfecho clínico não pôde ser estabelecido, uma vez que ele foi a óbito por atropelamento.

Conclui-se que, embora seja uma doença de pouca ocorrência no Brasil, a tuberculose felina deve ser considerada como diagnóstico diferencial de enfermidades infecciosas com sinais inespecíficos nessa espécie. Além disso, o tratamento pode ser eficaz mediante a associação de antibióticos, evidenciando-se melhora gradativa dos sinais clínicos, porém são necessários cuidados e precauções diante do ainda desconhecido poder zoonótico dessa enfermidade.

\section{REFERÊNCIAS}

GIBBENS, N. Mycobacterium bovis infection in cats. Vet. Rec., v.174, p.331-332, 2014.

GOKALP, G.; GULBAHAR, M. Y.; PEKMEZCI, D. et al. A Feline tuberculosis case. Kafkas Univ. Vet. Fak. Derg., v.17, p.155-157, 2011.

GUNN-MOORE D. A.; SHAW S. Mycobacterial disease in the cat. In Pract, v.19, p.493-501, 1997.

GUNN-MOORE, D.A.; Feline mycobacterial infections. Vet. J., v.201, p.230-238, 2014.

LISLE, G.W.; COLLINS, D.M.; LOVEDAY, A.S. et al. A report of tuberculosis in cats in New Zealand and the examination of strains of Mycobacterium bovis by DNA restriction endonuclease analysis. N. Z. Vet. J., v.38, p.10$13,1990$. 
MONIES, B.; JAHANS, K.; DE LA RUA, R. Bovine tuberculosis in cats. Vet. Rec., v.158, p.245-246, 2006.

MORETTI, L.D.; PAES, A.C.; PINHEIRO, S.R. Tuberculose em cães e gatos: artigo de revisão. Clín. Vet., v.48, 2004

MURRAY, A.; DINEEN A.; KELLY, P. et al. Nosocomial spread of Mycobacterium bovis in domestic cats. J. Feline Med. Surg., v.12, p.173$180,2015$.

RAMDAS, K.E.F.; LYASHCHENKO, K.P.; GREENWALD, R. et al. Mycobacterium bovis infection in humans and cats in Same Household, Texas, USA, 2012. Emerg. Infect. Diseases, v.21, p.480-483, 2015.
RAMOS, J.M.; HEINEMANN, M.B.; FERREIRA NETO, J.S. et al. Isolation and identification of Mycobacterium bovis in milk from cows in northeastern Brazil. Ciênc. Rural, v.46, p.2166-2169, 2016.

REILLY, L.M.O; DABORN, C.J. The epidemiology of Mycobacterium bovis infections in animals and man: a review. Tuber. Lung Dis., v.76, p.1-46, 1995.

RUFENACHT, S.; BOGLI-STUBER, K.; BODMER, T. et al. Mycobacterium microti infection in the cat: a case report, literature review and recent clinical experience. J. Feline Med. Surg., v.13, p.195-204, 2011.

UNE, Y.; MORI, T. Tuberculosis as a zoonosis from a veterinary perspective. Comp. Immunol. Microbiol. Infect. Diseases, v.30, p.415-425, 2007. 